Oxide Film of Alloys containing Small Percentages of Aluminium

When copper alloys containing more than 2 per cent aluminium were heated for many hours at a red heat $\left(800^{\circ}-900^{\circ} \mathrm{C}\right)$, no oxide scales were formed. In cases where several per cent of this element was added, the alloys even retained their characteristic golden yellow lustre, which is a very remarkable fact. Elements such as tin, zinc, nickel, manganese, magnesium, iron, etc., when added to copper do not produce this effect.

The oxidised surfaces were studied by means of cathode ray reflection. Copper surfaces exposed at a red heat gave the $\mathrm{CuO}$ pattern. (At lower temperatures, the $\mathrm{Cu}_{2} \mathrm{O}$ and a three ring pattern were also observed, as first pointed out by G. P. Thomson and (. A. Murison ${ }^{1}$.)

Upon heating alloys containing several per cent of aluminium at a red heat with a Bunsen burner, the surface in contact with air was blackened and gave the $\mathrm{CuO}$ pattern, while the surface imbedded in the oxidising flame remained bright and gave a pattern corresponding to that of pure $\gamma-\mathrm{Al}_{2} \mathrm{O}_{3}$. No diminution of the lustre of the latter surface was observable after continued heating.

The fact that alloys, containing only about 10 atomic per cent of aluminium, when heated with an insulficient supply of oxygen, become covered with a film of pure $\mathrm{Al}_{2} \mathrm{O}_{3}$ seems rather striking; because some copper oxide was anticipated. In the case where heating was done in air or in oxygen, the uppermost surface probably becomes covered with an extremely thin film of copper oxide, but beneath this layer, since oxygen is wanting, an $\mathrm{Al}_{2} \mathrm{O}_{3}$ film might be formed, and this in turn probably protects the inner part from further oxidation. Inasmuch as such a film is colourless, the alloy does not loose its golden lustre, even after prolonged exposure to red heat. The same may be true of iron alloys.

ICHIRÔ IITAKA.

Shizuo Miyake.

Institute of Physical and

Chemical Research,

Tokyo.

July 16.

${ }^{1}$ G. P. Thomson, Proc. Roy. Soc., A, 128, 649; 1930. C. A. Murison, Phil. Mag., 17, 96; 1934.

\section{Iridium Isotopes and their Nuclear Spin}

AN examination of the hyperfine structure of the are lines of iridium $\lambda \lambda 3800 \cdot 10,3513.67$ and $2924 \cdot 81 \mathrm{~A}$. radiated from a modified form of hollow cathode reveals that the three lines having a common lower level in the ground term $5 d^{8} 6 s^{4} F_{41}{ }^{1}$ are identical in structure. The hyperfine components are therefore ascribed to a spin splitting of the ground term with the upper levels unsplit. $\lambda 3513 \cdot 67 \mathrm{~A}$. $\left(5 d^{8} 6 s^{4} F_{41}-\right.$ $\left.5 d^{8} 6 p^{4} G^{0}{ }_{4 \frac{1}{2}}\right)$ exhibits the following structure :

$\begin{array}{rcc}d v \text { in cm.-1 } & \text { (Int.) } & \text { Remarks } \\ +0.072 & (7) & \text { This component is diffuse and appears } \\ & & \text { almost as a continuous patch between } \\ 0.000 & (22) & +0.072 \text { and } 0.000 \text {, indicating the } \\ -0.073 & (13) & \text { presence of an expected satellite at } \\ -0.145 & (9) & +0.033(9) . \text { (vide Fig. 1.) }\end{array}$

The observed structure is accounted for uniquely by assuming two isotopes of masses $19 \mathrm{l}$ and 193 with nuclear spins of $\frac{1}{2}$ and $\frac{8}{2}$ respectively. The ratio of the magnetic moments of the two nuclei is nearly $-1 \cdot 0$. The isotope displacement in $5 d^{8} 6 s{ }^{4} F_{4}$ is $0.057 \mathrm{~cm}^{-1}$, with the heavier isotope lying deeper, as in the arc lines of copper and thallium. ${ }^{2}$ The incom. pletely resolved patterns of some other Ir I lines $\lambda \lambda 3220 \cdot 79,2694 \cdot 22,2664 \cdot 77$ and $2639 \cdot 70 \mathrm{~A}$. support the above conclusions. The existence of isotope shift favours the suggestion that the ground term is a ${ }^{4} F_{4}$ term arising from an electron configuration $5 s^{2} 5 p^{6} 5 d^{8} 6 s$ in preference to a ${ }^{2} D_{3 / 2}$ term from $5 s^{2} 5 p^{8} 5 d^{9} .^{3}$

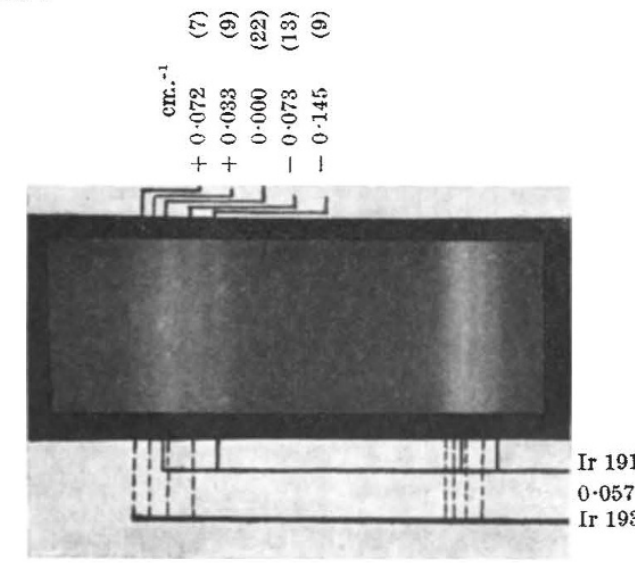

Fre. 1. Structure pattern of Ir I, $3513.67 \mathrm{~A}$

obtained with a Hilger quartz Lummer plate, $3.45 \mathrm{~mm}$. thick, $20 \mathrm{~cm}$. long.

Iridium is one of the few elements the isotopic constitution of which has not so far been revealed by the mass-spectrograph. Judging from a visual estimate of the intensities of the components, the relative abundance of the isotopes 191 and 193 is $1: 2$, giving a value, perhaps a little too low, of $192 \cdot 4$ for the atomic weight of iridium. It appears, however, that the atomic weight of the iridium must be less than 193 ; there is considerable disagreement in the values of atomic weight given by several investigators, which range from $192 \cdot 59$ to $193 \cdot 40$. The existence of a heavier isotope like 195 is ruled out by the fact that usually there is no isobare in appreciable quantity for an isotope of an element with odd atomic number ; and platinum has been previously shown to contain the isotope Pt 195 to the extent of nearly 30 per cent. ${ }^{4}$

Details will appear in the Proceedings of the Indian Academy of Sciences.

B. VENKateisachar.

L. Sibaiya.

Department of Physics, Central College,

Bangalore. Aug. 7.

${ }^{1}$ Albertson, Phys. Rev., 42, 443 ; 1932

${ }^{2}$ Venkatesachar and Sibaiya, Proc. Ind. Acad. Sci., 1, 13; 1934

${ }^{3}$ Meggers and Laporte, Phys. Rev., 28, 660.

Meggers and Laporte, Phys. Rev., 28, 660; 1926. Acad. Sci., 1, $955 ; 1935$. ibid., 2, 101; 1935.

\section{$K$-Series of Magnesium and Sodium}

I HAVE already published ${ }^{1}$ some results obtained in the region of long wave-lengths with the ionic tube designed and constructed by me with Prof. Dolejsek ${ }^{2}$. With this ionic tube and with a new focusing method, the principle of which will be described elsewhere, I have obtained some new results which show the great efficacy of our apparatus for long wave-lengths of X-spectra.

As an example of what can be obtained by our 